\title{
The moderating role of psychological capital in the relationship between job stress and the outcomes of incivility and job involvement amongst call centre employees
}

\begin{abstract}
Authors:
Sarah B. Setar ${ }^{1}$

Johanna H. Buitendach ${ }^{1}$

Herbert Kanengoni ${ }^{2}$

\section{Affiliations:}

${ }^{1}$ School of Applied Human

Sciences, University of

KwaZulu-Natal, Howard

College Campus, South Africa

${ }^{2}$ Department of Industrial Psychology, University of the Free State, South Africa

Correspondence to:

Johanna Buitendach

Email:

buitendach@ukzn.ac.za

Postal address:

School of Applied Human

Sciences, King George

V Avenue, Durban 4041,

South Africa

Dates:

Received: 12 Nov. 2013

Accepted: 29 Oct. 2014

Published: 10 Dec. 2015

How to cite this article: Setar, S.B., Buitendach, J.H., \& Kanengoni, H. (2015) The moderating role of psychological capital in the relationship between job stress and the outcomes of incivility and job involvement amongst call centre employees. SA Journal of Industrial Psychology/SA Tydskrif vir Bedryfsielkunde, 41(1), Art. \#1183, 13 pages. http://dx.doi.org/10.4102/ sajip.v41i1.1183
\end{abstract}

Read online:

Scan this $Q R$ code with your smart phone or mobile device to read online.
Orientation: South African call centres were found to rank amongst those with the highest degree of performance monitoring and feedback. This revelation comes at a time when many scholars concur that research has not entirely succeeded in helping organisations overcome the negative aspects of work and enhance the positive aspects of work, such as job involvement.

Research purpose: This study sought to examine the relationship between job stress, job involvement and the display of uncivil behaviour amongst call centre employees, whilst also studying the role of psychological capital (PsyCap) in this relationship.

Motivation for the study: The study was prompted by the scarcity of research in the area of PsyCap and job involvement, none of which has examined relationships between job stress and the outcomes of incivility and job involvement and the moderating role of PsyCap in this relationship, focusing on call centre employees.

Research design, approach and method: A quantitative design employed a cross-sectional survey to collect data from 104 South African call centre employees using a biographical data sheet, the PsyCap Questionnaire, Job Stress Scale, Uncivil Workplace Behaviour Scale and the Job Involvement Scale.

Main findings: PsyCap and uncivil workplace behaviour were negatively related, whilst PsyCap and job involvement were positively related. Job stress held predictive value for incivility and the hostility subscale. Hierarchical regression analysis indicated that PsyCap did not moderate the relationship between job stress and incivility and neither did it moderate the relationship between job stress and job involvement.

Practical implications: Organisations should work on minimising stressors within the workplace in order to enhance the PsyCap of employees, which not only lowers the risk of incivility displayed by employees but also ensures greater employee involvement.

Contribution/value-add: Although previous studies have examined the relationship between stress, incivility and job involvement, no studies have been conducted examining the role of PsyCap in this relationship, especially, more importantly, sampling call centre employees.

\section{Introduction}

Positive psychology is an area of study that emerged as a result of criticisms levelled against the discipline of psychology for its preoccupation with diagnosing and removing the negative aspects of human thinking and behaviour (human pathology) rather than identifying and enhancing the positive aspects or strengths of individuals (Seligman \& Csikszentmihalyi, 2000). In keeping with this idea of seeking to enhance the positive aspects of human behaviour, research in the area of positive psychology has increased considerably in recent years. Along with the area of positive psychology itself, the literature in the area of positive organisational behaviour and the application of positive psychology in the workplace has also grown considerably (Luthans, 2002). A fairly new concept originating in the field of positive organisational behaviour, which has not received enough attention amongst researchers but has shown much promise for the future of positive psychology, is psychological capital. Psychological capital (PsyCap) is a positive psychological state that can be developed and enhanced within individuals at any point in their life due to its state-like nature (Lewis, 2011; Luthans, Youssef \& Avolio, 2007). PsyCap is characterised by the possession of these four qualities in an individual: self-efficacy 
(a sense of competence in one's ability to carry out a particular task), resilience (the ability to bounce back from difficulty), hope (positive expectations for the future) and optimism (forming positive attributions for negative outcomes). It is believed that these four qualities can be developed within an individual at any time. These four constructs have been shown to have beneficial effects both individually and as the combined construct of PsyCap. Despite the increasing body of research in the area of positive psychology and positive organisational behaviour (Luthans \& Youssef, 2004), research findings have not entirely succeeded in helping organisations overcome the negative aspects of work, such as the experience of job stress and the display of incivility within the workplace, and enhance the positive aspects of work, such as job involvement. In this regard, the current study attempted to examine these constructs in relation to PsyCap with the aim of improving the understanding of these constructs and the relationships amongst them, whilst also seeking to determine the role played by PsyCap in the relationships amongst these constructs.

\section{Background to the study}

A recent study conducted in different organisations across nine industry sectors in South Africa reported that a dilemma is prevalent in terms of efficiency and quality in South African call centres (Banks \& Roodt, 2011). In a similar study conducted in a call centre environment, Janse van Rensburg, Boonzaier \& Boonzaier (2013) concede that both the content and context of jobs need to be addressed to increase the personal and job resources of call centre representatives. Of note also is that call centres are regarded as providing particularly stressful work conditions for employees, mainly due to increased demands for performance and through the implementation of performance monitoring mechanisms, which serve to increase tension between managers and employees (Benner, Rahmat \& Lewis, 2007). These performance monitoring mechanisms have been linked to high levels of stress and increased staff turnover in many call centres, especially when very little discretion is exercised in providing feedback to employees (Benner et al., 2007). South African call centres were found to rank amongst those with the highest degree of performance monitoring and feedback, exceeded only by South Korean and Indian call centres (Holman, Batt \& Holtgrewe, 2007). This high degree of performance monitoring and feedback, and its known effect of increasing job stress, suggests that South African call centre employees may experience a high level of stress within the workplace. In this regard Banks and Roodt (2011) posited that South African organisations should assess the alignment between their organisational vision, the strategic intentions of their call centres and the performance measures they use. Although previous research (e.g. Van Jaarsveld, Walker \& Skarlicki, 2010) has examined the effects of incivility within a call centre setting, the focus was on the spiralling effect of incivility as proposed by Andersson and Pearson (1999), in which customer incivility provoked uncivil responses from call centre employees. This study, however, sought to examine the relationship between job stress and the display of uncivil behaviour amongst call centre employees, whilst also studying the role of PsyCap in this relationship.

Despite the concept of incivility overlapping with that of counterproductive work behaviour (CWB), few studies have examined the relationship between job stress and incivility, with Penney and Spector's (2005) study being the first to study both constructs in relation to each other, followed by the study conducted by Roberts, Scherer and Bowyer (2011), which assessed the moderating role of PsyCap in this relationship. Although previous studies have examined the relationship between stress and job involvement (e.g. Lata-Juyal, 2012; Ouyang, 2009), no studies have been conducted examining the role of PsyCap in this relationship. Importantly, no previous study has examined this relationship in a sample of call centre employees. Additionally, the scarcity of South African research in the area of PsyCap (Rothmann \& Cilliers, 2007) and the small number of studies conducted on job involvement, none of which studied job involvement in relation to PsyCap, job stress or incivility, suggest a need for such research to be conducted. This study attempted to identify the potential link between job stress and the outcomes of incivility and job involvement and the moderating role of PsyCap in this relationship, using a sample of South African call centre employees.

Two theories underpin this study. The first is the job stress model developed by Spector and Fox (2005), which explains the relationship between job stress and CWB, which is closely related to but distinct from incivility. The model aids in explaining the relationship between job stress and CWB, stating that an employee's appraisal of a threatening situation as being stressful results in an emotional reaction, which results in them acting out through the display of CWB or, in this case, incivility. The second theory is the broadenand-build theory of positive emotions, which states that an individual's experience of positive emotions tends to broaden their momentary thought-action repertoire and build their enduring personal resources (Fredrickson, 2004). Therefore, an individual's possession of the positive traits underlying PsyCap (self-efficacy, hope, optimism and resilience) may result in the broadening and building upon of these positive psychological resources in the workplace to achieve the positive outcome of job involvement. Positive emotions play a significant role in helping individuals adopt broader ways of thinking and behaving; in addition, the personal resources gained during the experience of these positive emotion states are durable.

\section{Research objectives}

Taking into consideration the background and motivation for this study, the objectives of this study were:

- To assess the reliability of the PsyCap Questionnaire (PCQ), Job Stress Scale (JSS), Uncivil Workplace Behaviour Scale (UWBS-R) and Job Involvement Scale (JIS) for call centre employees at a selected organisation.

- To determine the relationship between PsyCap, job stress, incivility and job involvement. 
- To determine whether PsyCap and job stress hold any predictive value for the outcomes of incivility and job involvement.

- To determine whether PsyCap plays a moderating role in the job stress-incivility relationship.

In order to address the abovementioned research objectives, the following research questions were asked:

- What is the reliability of the PCQ, JSS, UWBS-R and JIS for call centre employees at a selected organisation?

- What is the relationship between PsyCap, job stress, incivility and job involvement?

- Are job stress and PsyCap predictors of incivility?

- Are job stress and PsyCap predictors of job involvement?

- To what extent does PsyCap moderate the relationship between job stress and incivility or job involvement?

\section{Literature review}

Previous research on PsyCap has studied each of the four underlying constructs of PsyCap individually in relation to stress, with Bandura (2008) looking at the relationship between coping self-efficacy and stress, Totterdell, Wood and Wall (2006) studying optimism and stress, Snyder (2000) studying hope and its relationship with various symptoms associated with stress and Tugade and Fredrickson (2004) providing support for the positive influence of resilience in helping individuals adapt and maintain emotional stability within the workplace. This indicates the importance of each of the four constructs underlying PsyCap in attempting to overcome the negative effects of stress.

\section{Psychological capital}

The concept of PsyCap, originating in the field of positive organisational behaviour, is defined as:

an individual's positive psychological state of development characterised by: (1) having confidence (self-efficacy) to take on and put in the necessary effort to succeed at challenging tasks; (2) making a positive attribution (optimism) about succeeding now and in the future; (3) persevering toward goals, and when necessary, redirecting paths to goals (hope) in order to succeed; and (4) when beset by problems and adversity, sustaining and bouncing back and even beyond (resilience) to attain success. (Luthans et al., 2007, p. 3)

Important to note is that PsyCap is regarded as a psychological state.

Psychological states are transient human phenomena, meaning that they are changeable and can be developed within individuals, thereby suggesting that PsyCap can be developed in an individual at any time during the progression of their life (Lewis, 2011). Psychological capital adheres to the basic premise of positive psychology, which seeks to encourage and develop positive qualities within individuals (Seligman \& Csikszentmihalyi, 2000).

Self-efficacy, according to Wood and Wood (1996, p. 456), can be regarded as a 'person's belief in his or her ability to perform competently in whatever is attempted'. Selfefficacy is, therefore, a state of self-belief (Lewis, 2011). In an organisational context, self-efficacy refers to an:

employee conviction or confidence about his or her abilities to mobilise the motivation, cognitive resources or courses of action needed to successfully execute a specific task within a given context. (Stajkovic \& Luthans, 1998, p. 66)

An individual possessing a high level of self-efficacy would, therefore, approach tasks with greater confidence as a greater likelihood of success would be perceived. Self-efficacy is generally developed as a result of attaining experience and mastery over certain tasks or areas of knowledge. It is also achieved through learning and vicarious modelling, that is by watching others succeed at a task or in a particular area (Lewis, 2011). Optimism, according to Tiger (1971), is regarded as:

a mood or attitude associated with an interpretation about the social and material - one which the evaluator regards as socially desirable to his [or her] advantage, or for his [or her] pleasure. (p. 18)

Seligman and Csikszentmihalyi (2000) define optimism as an attributional style in which an individual regards positive events as being caused by internal, permanent and pervasive factors whilst negative events are viewed as occurring due to external, temporary and situation-specific factors. Optimism is, therefore, regarded as a state of explanation. Individuals with 'realistic' or flexible optimism are likely to show high levels of commitment toward their organisations (Peterson, 2000) which, in turn, could lead to heightened performance (Luthans \& Youssef, 2004).

Hope, according to Lewis (2011), is regarded as a state of mind. It is defined as a 'positive emotional state that is based on an interactively derived sense of successful (a) agency (goal directed energy) and (b) pathways (planning to meet goals)' (Snyder, Irving \& Anderson, 1991, p. 287). Therefore, hope can be regarded as based on three major conceptual foundations, namely agency, pathways and goals (Luthans, 2002). Agency, in this case, refers to an individual possessing the will to achieve a desired effect (Snyder, 2000). Individuals in possession of high levels of hope are able to foresee possible obstacles to achieving their goals and, therefore, adopt a contingency planning strategy by identifying a range of alternate pathways through which their goals may be achieved (Snyder, 2000). This suggests that hope requires the ability to effectively plan and set goals for the future so that one's sense of hope is regarded as realistic and the things that one hopes for may be attained. Resiliency, according to Masten and Reed (2002, p. 75), is 'characterised by patterns of positive adaptation in the context of significant adversity or risk'. Luthans (2002, p. 702) defines resilience as a PsyCap construct as the 'positive psychological capacity to "bounce back" from adversity, uncertainty, conflict, failure, progress, increased responsibility or even positive change'. Whilst self-efficacy, hope and optimism are typically expressed proactively, resilience is usually exhibited as a 
response or reaction to a setback (Avey, Luthans \& Youssef, 2006). Common characteristics of resilient individuals include a staunch acceptance of reality, a deep belief in the meaningfulness of life and an ability to adapt and improvise in the face of significant change (Coutu, 2002). Resilience can be developed through individuals being repeatedly exposed to increasingly difficult situations and learning from these situations in a productive way (Lewis, 2011).

\section{Job stress}

Stress refers to the mental and physical condition experienced when individuals adjust or adapt to the environment (Coon \& Mitterer, 2007). Job stress, according to Beehr and Newman (1998), refers to 'any aspects due to which employees feel uneasiness in a workplace'. Job stress is understood to be subjective in nature, as its assessment is based on the perceptions of individuals and whether they believe that they can manage and cope with the various physical, environmental and psychosocial stressors prevalent within the workplace (Herbert, 2011). The relationship between job stress and incivility has been studied previously, with Roberts et al. (2011) finding a significant positive relationship between job stress and the subsequent display of incivility. Penney and Spector (2005) studied incivility as a stressor in the workplace, which was shown to provoke individuals to engage in CWB. According to Lazarus and Folkman (1984), job stress arises as a result of an imbalance between the particular demands of a job and the resources possessed by an employee to meet those demands. However, not all stress is negative and harmful as, despite the negative connotations commonly associated with stress, it is not inherently a negative construct (Herbert, 2011). Whilst the definitions put forward by Lazarus and Folkman (1984) and Beehr and Newman (1998) refer to the negative side of stress, namely 'distress', the positive side of stress is expressed in the term 'eustress'. Eustress is a form of 'good stress' which is usually experienced whilst performing activities that are challenging, rewarding and energising for an individual (Coon \& Mitterer, 2007). This makes job stress an important area of study as it would prove beneficial to identify further negative outcomes of job stress (such as incivility) and possible moderating factors (such as PsyCap) in this relationship.

\section{Incivility}

Incivility is a widespread phenomenon in the workplace and has far-reaching implications for effective organisational functioning (Pearson \& Porath, 2009). Despite being low in intensity and mild in nature, acts of incivility have farreaching implications for organisations. Incivility, according to Andersson and Pearson (1999), is defined as:

a low-intensity deviant behaviour with ambiguous intent to harm the target, in violation of workplace norms for mutual respect. Uncivil behaviors are characteristically rude and discourteous, displaying a lack of regard for others. (p. 457)

Uncivil behaviour tends to be of a milder nature and are regarded as low-intensity behaviour that can be verbal or non-verbal, active or passive, but never physical (Martin \&
Hine, 2005). Although characteristic of deviant behaviour, incivility can be differentiated from CWB based on three main factors (Andersson \& Pearson, 1999); CWB is typically carried out with the intention to harm an individual or organisation, whereas incivility, although harmful, is not necessarily carried out intentionally. Acts of incivility are not overtly threatening or hostile and, therefore, can be rather ambiguous whereas with CWB, the hostility and intent to harm others is clearly displayed. Due to the mild and ambiguous nature of uncivil behaviour, intent to harm can be denied easily by the perpetrator (Penney \& Spector, 2005). Of note also is that incivility is regarded as a stressor in Spector and Fox's (2005) job stress model, whereas CWB is regarded as a response or reaction to stress. Research conducted by Roberts et al. (2011) has, however, indicated that incivility is not only a stressor, but also an outcome of stress.

\section{Job involvement}

Job involvement refers to the level of an individual's psychological identification with their work and the significance of that work to one's self-image (Lodahl \& Kejner, 1965). Kanungo (1982) echoes this definition by regarding job involvement as a cognitive belief state that reflects an individual's psychological identification and level of involvement in their job. Kanungo distinguishes job involvement from work involvement, claiming that work involvement refers to an individual's personal code of ethics regarding work in general (i.e. their normative beliefs), which are formed based on the individual's previous experiences and social interactions in the workplace. On the other hand, job involvement considers an individual's cognitive beliefs regarding a specific job. Various attempts have previously been made to study job involvement in South Africa. Govender and Parumasur (2010) examined the relationship between employee motivation and job involvement, finding that high levels of employee motivation correlated significantly with high levels of job involvement. Unlike other research conducted on job stress and incivility in a call centre setting, this study sought to examine the moderating role of PsyCap in the relationship between job stress and the outcomes of incivility and job involvement amongst call centre employees in South Africa.

\section{What will follow}

In the following section the research design is discussed followed by a presentation of both descriptive and inferential statistical results. Thereafter, the findings are interpreted and discussed in the discussion section, which also includes conclusions and implications for practice, limitations of the study and, finally, discussion of the directions for future research.

\section{Research design Research approach}

This cross-sectional study followed a quantitative research design because it emphasises empirical methods of data collection and analysis through the use of statistical methods 
and a widespread belief in the objectivity and generalisability of research findings (Durrheim \& Painter, 2006).

\section{Research method}

\section{Research participants}

The current study specifically assessed 104 conveniently sampled call centre employees at a selected organisation in Durban. This is because these call centre employees were a very specific and available sample that represented the population under study.

Of the call centre agents sampled in this study, $73.1 \%$ were female participants, with male participants constituting $26.9 \%$. The sample consisted mainly of younger participants with most of the participants in the 25-35 age group (57.7\%), whilst $40.4 \%$ were younger than 25 years and $1.9 \%$ belonged to the 36-45 age group. Participants were predominantly African (61.5\%), followed by a smaller number of Indian participants $(27.9 \%)$ then mixed-race participants $(9.6 \%)$ with white participants comprising the lowest percentage $(1.0 \%)$. The majority of sampled participants were single (85.6\%), $11.5 \%$ were married, $1.0 \%$ divorced and only $1.9 \%$ indicated that they were living with a spouse. Most of the participants had worked at the organisation for less than six years $(93.3 \%)$, whilst $6.7 \%$ had worked in the organisation for between 6 and 10 years. The highest qualification attained by $74 \%$ of the population was a Matric certificate, $21.2 \%$ had a diploma, and $3.8 \%$ had obtained a degree and only $1.0 \%$ held a postgraduate degree.

\section{Measuring instruments}

Instruments used to collect data in this study included the Psychological Capital Questionnaire (Luthans et al., 2007), the Job Stress Scale (Parker \& DeCotiis, 1983), the revised Uncivil Workplace Behaviour Scale (Martin \& Hine, 2005) and the Job Involvement Scale (Lodahl \& Kejner, 1965).

TABLE 1: Participants' demographic information.

\begin{tabular}{llcc}
\hline Variable & Category & $f$ & $\mathbf{\%}$ \\
\hline Race group & African & 64 & 61.5 \\
& White & 1 & 1.0 \\
& Mixed-race & 10 & 9.6 \\
& Asian/Indian & 29 & 27.9 \\
Gender & Female & 76 & 73.1 \\
& Male & 28 & 26.9 \\
Qualifications & Matric certificate & 77 & 74.0 \\
& Diploma & 22 & 21.2 \\
& Degree or equivalent & 4 & 3.8 \\
& Postgraduate degree & 1 & 1.0 \\
Age group (years) & $<25$ & 42 & 40.4 \\
& $25-35$ & 60 & 57.7 \\
Tenure (years) & $36-45$ & 2 & 1.9 \\
& $<6$ & 91 & 93.3 \\
Marital status & $6-10$ & 7 & 6.7 \\
Tenure (years) & Single & 89 & 85.6 \\
& Divorced & 1 & 1.0 \\
\hline
\end{tabular}

f, frequency
Psychological Capital Questionnaire: The PCQ (Luthans et al., 2007) is a 24-item scale divided into four subscales, with six items in each subscale measuring the four main constructs of PsyCap: resilience, hope, optimism and self-efficacy. The PCQ draws from previously published standardised measures for each of the four constructs mentioned above: a six-item scale consisting of statements such as 'I feel confident helping to set targets and goals in my work area'. Included also in the PCQ is the $r$ items consisting of statements such as 'If I should find myself in a jam, I could think of many ways to get out of it' and 'At the present time, I am energetically pursuing my goals', which is an example of the hope subscale. Lastly, the items measuring optimism included statements such as 'There are lots of ways around any problems that I am facing now' and 'In uncertain times, I usually expect the best'. Bosman, Buitendach and Rothmann (2005), in a South African study, determined a Cronbach's alpha coefficient of 0.70 , indicating that this measure has adequate internal consistency.

Job Stress Scale: The JSS (Parker \& DeCotiis, 1983) consists of 13 items rated on a four-point Likert scale ( 1 = strongly disagree; 4 = strongly agree). This measure consists of two subscales, namely time stress and job-related anxiety. Five items measure job-related anxiety by using statements such as 'I have felt fidgety or nervous as a result of my job' and 'Sometimes when I think about my job I get a tight feeling in my chest'. Statements that measure time stress include 'I frequently get the feeling I am married to the company' and 'I have too much work and too little time to do it in'. Parker and DeCotiis (1983) determined Cronbach's alpha coefficients as follows: 0.86 for time stress and 0.74 for job-related anxiety. Almendra (2010) determined a Cronbach's alpha coefficient of 0.91 for the total scale and alpha values of 0.86 for the time stress subscale and 0.74 for job-related anxiety.

Uncivil Workplace Behaviour Scale: The UWBS developed by Martin and Hine (2005) consists of 17 items divided into four subscales which assess four types of incivility, namely privacy invasion, exclusionary behaviour, hostility and gossiping. Items measuring each of these factors include: 'Took items from a co-worker's desk without prior permission' (privacy invasion), 'Did not consult a co-worker in reference to a decision they should have been involved in' (exclusionary behaviour), 'Spoke to a co-worker in an aggressive tone of voice' (hostility) and 'Talked about a coworker behind their back' (gossiping). Participants were required to indicate how often they have displayed uncivil behaviour towards their colleagues and supervisors by rating their responses on a five-point Likert scale ( 1 = never; 5 = very often). A high score indicates that incivility has been displayed regularly by the respondent. Martin and Hine (2005) determined a Cronbach's alpha coefficient of 0.92 for the overall scale and Cronbach's alpha values over 0.80 for each of the subscales. Additionally, Roberts et al. (2011) found a high internal consistency for the overall scale ( $\alpha=0.93$ ), whilst acceptable reliability levels were found for each of the subscales. 
Job Involvement Scale: The JIS is a 20-item scale developed by Lodahl and Kejner (1965) and is one of the most widely used instruments for measuring job involvement. It measures the extent to which one's job occupies a central position in one's life and looks at both levels of psychological identification and performance-self-esteem contingency notions (Kanungo, 1982). Responses are rated on a five-point Likert scale ( 1 = strongly disagree; 5 = strongly agree). This scale includes statements such as 'The major satisfaction in my life comes from my job', 'I usually show up for work a little early, to get things ready' and 'I have other activities more important than my work'. Ramsey, Lassk and Marshall (1995) found a Cronbach's alpha coefficient of 0.79 for the complete 20-item scale. Govender and Parumasur (2010), in a South African study, used the 22-item version of this scale and found a Cronbach's alpha coefficient of 0.70 for the total scale, indicating that the scale displayed adequate internal consistency.

\section{Research procedure}

The data collection process was conducted over a two-week period, after which the completed questionnaires were collected. Firstly, permission was sought from the human resource (HR) office to collect data in the organisation. The researchers presented an ethical clearance certificate from the institution's research office, together with a sample of the questionnaire booklet, in the briefing meeting. Employees' anonymity and confidentiality were maintained at all times and assurance that the research findings would not harm either the employees or the organisation in any way and information on the use of the results was given through the consent form that accompanied each questionnaire. With the assistance of the HR office 150 questionnaires were distributed in the organisation and explanation of the purpose of the research was provided to the employees. A total of 104 usable questionnaires were collected after two weeks.

\section{Statistical analysis}

Data analysis was conducted by means of the SPSS program, version 21. In order to determine the factor structure of the instruments as well as to assess the number of factors present in the instrument, exploratory factor analysis was conducted. Descriptive statistics, in the form of means, medians, standard deviations, kurtosis and skewness (Howell, 2008), were employed in the data analysis to describe and make conclusions based on logical reasoning about a population based on results obtained from studying a sample drawn from the population. Cronbach's alpha coefficients were used to determine the reliability of the measuring instruments (Clark \& Watson, 1995). In order to determine the relationship between the various constructs studied, the Pearson product-moment correlation coefficients were used. Effect sizes, indicative of the significance of obtained results (Cohen, 1988), were used to determine the practical significance of the results. The Pearson correlation analysis was conducted between total scales and their individual subscales in order to determine the relationships between them. Lastly, multiple regression analysis was conducted to assess the contribution of the predictor variable, job stress, on the outcomes of incivility and job involvement and the moderating role of PsyCap in this relationship. Specifically, multiple regression was conducted to determine if PsyCap moderates the relationship between job stress and incivility and the relationship between job stress and job involvement.

\section{Results \\ Descriptive statistics}

Descriptive statistics for all three measuring instruments are displayed in Table 2.

Negative skewness values on the PCQ and JIS indicate that scores on these measures tend to be clustered around the high end of the distribution. Positive skewness values for the JSS and UWBS indicate that scores tend to be clustered around the low end of the distribution. Whilst skewness scores for the PCQ, JSS and JIS fall within the acceptable range of between -2 and 2, scores on the UWBS appear to be a higher than the acceptable range. However, inspection of the distribution of scores on the histogram and normal probability plots indicates that the scores appear to be relatively normally distributed. Positive kurtosis values for the PCQ and UWBS indicate that the distribution of scores for these measures is rather peaked (clustered at the centre). All kurtosis values are above 0 , indicating that the distribution is not a flat one. After assessing the data for normality, the difference in values for the mean and 5\% trimmed mean was small for each of the scales and subscales examined for extreme scores. Assessment of the Kolmogorov-Smirnov values indicated

TABLE 2: Psychometric characteristics of instruments $(N=104)$.

\begin{tabular}{|c|c|c|c|c|c|c|c|}
\hline Variable & Minimum & Maximum & M & SD & Skewness & Kurtosis & $\alpha$ \\
\hline Psychological Capital Questionnaire & 28 & 102 & 75.60 & 14.852 & -1.052 & 1.537 & 0.89 \\
\hline Hopeful-confidence & 12 & 72 & 52.49 & 12.427 & -1.387 & 2.163 & 0.90 \\
\hline Optimism & 9 & 30 & 23.14 & 4.461 & -0.753 & 0.654 & 0.73 \\
\hline Job Stress Scale & 12 & 45 & 27.51 & 7.160 & 0.174 & -0.290 & 0.91 \\
\hline Uncivil Workplace Behaviour Scale & 16 & 70 & 22.69 & 8.221 & 2.681 & 11.174 & 0.91 \\
\hline Privacy invasion and exclusion & 9 & 41 & 11.40 & 4.462 & 3.900 & 20.351 & 0.90 \\
\hline Job Involvement Scale & 28 & 72 & 49.90 & 10.268 & -0.163 & -0.494 & 0.83 \\
\hline Expression of being job involved & 13 & 50 & 30.43 & 7.276 & -0.207 & 0.271 & 0.81 \\
\hline Response to work & 7 & 30 & 19.16 & 5.257 & -0.098 & -0.612 & 0.80 \\
\hline
\end{tabular}

M, mean; SD, standard deviation; $\alpha$, alpha. 
significance levels below 0.05 for the PCQ, JSS and UWBS. This suggests a violation of the assumptions of normality. The significance values for the JIS, JIS factor 1 and JIS factor 2 are above 0.05 , however, indicating an alignment with the assumptions of normality for this measure. The Cronbach's alpha coefficients for all four measures and subscales equal or exceed the preferred reliability level of 0.70 threshold determined by Nunnally and Bernstein (1994), indicating high internal consistency.

\section{Exploratory factor analysis}

The 24 items of the PCQ were subjected to principal components analysis (PCA) using SPSS version 21. An assessment of the suitability of the data for factor analysis indicated the presence of many correlation coefficients of 0.30 and above in the correlation matrix. As shown in Table 3, the principal components analysis initially revealed the presence of seven components with eigenvalues above 1, explaining $27.664 \%$ of the variance. However, the loading of items in the pattern matrix appeared to be scattered and very few items loaded significantly on certain components, with no items loading significantly on the seventh component. This resulted in the decision to further reduce the number of components by a forced component solution until two components explaining a total of $37.228 \%$ of the variance were retained. However, during subsequent analysis, items $13,14,15,16,17,20$ and 23 were excluded from the final scale because they did not load significantly on either component. The new scale consisted of component 1 (items 1-12) and component 2 (items 18, 19, 21, 22, 24). Items for self-efficacy and hope loaded onto component 1 which was renamed 'hopeful confidence'. Most of the items in component 2, named optimism in this study, originally loaded on to the optimism subscale with the exception of item 18, originally from the resilience subscale.

TABLE 3: Exploratory factor analysis of the Psychological Capital Questionnaire.

\begin{tabular}{|c|c|c|c|}
\hline \multirow[t]{2}{*}{ Item } & \multicolumn{2}{|c|}{ Component } & \multirow[t]{2}{*}{ Reliability } \\
\hline & 1 & 2 & \\
\hline Hopeful-confidence & - & - & 0.90 \\
\hline Item 8 & 0.803 & - & - \\
\hline Item 6 & 0.730 & - & - \\
\hline Item 7 & 0.728 & - & - \\
\hline Item 1 & 0.713 & - & - \\
\hline Item 4 & 0.693 & - & - \\
\hline Item 11 & 0.684 & - & - \\
\hline Item 2 & 0.681 & - & - \\
\hline Item 10 & 0.674 & - & - \\
\hline Item 3 & 0.667 & - & - \\
\hline Item 5 & 0.632 & - & - \\
\hline Item 9 & 0.541 & - & - \\
\hline Item 12 & 0.514 & - & - \\
\hline Optimism & - & - & 0.73 \\
\hline Item 19 & - & 0.784 & - \\
\hline Item 24 & - & 0.695 & - \\
\hline Item 21 & - & 0.663 & - \\
\hline Item 18 & - & 0.645 & - \\
\hline Item 22 & - & 0.598 & - \\
\hline- & - & - & - \\
\hline Overall & - & - & 0.89 \\
\hline
\end{tabular}

The 13 items of the JSS were similarly subjected to PCA using SPSS version 21. This revealed the presence of two components with eigenvalues above 1, explaining $45.668 \%$ and $9.555 \%$ of the variance respectively, but only two items loaded significantly on component 2. A one-component solution resulted in the decision to retain component 1 , which explained a total of $45.668 \%$ of the variance, with all items loading significantly $(p \geq 0.45)$ except for item 13 , which had a very low value of 0.176 and was therefore excluded from the scale for subsequent analysis.

PCA was conducted on the 17 items of the UWBS. Assessment of the suitability of data for factor analysis indicated the presence of many correlation coefficients of 0.30 and above in the correlation matrix. The suitability of the data for analysis was assessed. PCA initially indicated the presence of four components with eigenvalues above 1, explaining $45.143 \%, 9.063 \%, 7.517 \%$ and $6.490 \%$ of the variance. Inspection of the scree plot indicated a clear break after the second component. After forcing a reduced number of factors, a two-component solution explained a total of $54.206 \%$ of the variance, with component 1 contributing $45.143 \%$ and component 2 contributing $9.063 \%$. The twocomponent factor structure does not fit the four-component structure determined in previous research, which was as follows: exclusionary behaviour (items 1, 3, 5, 11, 16), gossiping (items $2,6,8,12)$, hostility $(4,10,15,17)$ and privacy invasion $(7,9,13,14)$. Instead, the two-component structure determined in this study consisted of the following items on each component: component 1 (items 5, 7, 8, 9, 11, 12, 13, 14, 16) and component 2 (items 2, 3, 4, 6, 10, 15, 17). Most of the items that loaded on component 1 originally belonged to the privacy invasion and exclusionary behaviour subscales; hence, these two subscales were combined to create the 'privacy invasion and exclusionary behaviour' subscale. Items that loaded significantly on component 2 originally

TABLE 4: Exploratory factor analysis of the Uncivil Workplace Behaviour Scale.

\begin{tabular}{lccc}
\hline Item & \multicolumn{2}{c}{ Component } & Reliability \\
\cline { 2 - 3 } & \multicolumn{1}{c}{$\mathbf{2}$} & $\mathbf{2}$ & \\
\hline Privacy invasion and exclusionary behaviour & & & $\mathbf{0 . 9 0}$ \\
Item 7 & 0.851 & - & - \\
Item 9 & 0.842 & - & - \\
Item 13 & 0.825 & - & - \\
Item 8 & 0.802 & - & - \\
Item 11 & 0.748 & - & - \\
Item 5 & 0.648 & - & - \\
Item 12 & 0.643 & - & - \\
Item 16 & 0.493 & - & - \\
Item 14 & 0.470 & - & - \\
Hostility & - & - & $\mathbf{0 . 8 4}$ \\
Item 10 & - & 0.935 & - \\
Item 17 & - & 0.810 & - \\
Item 15 & - & 0.717 & - \\
Item 6 & - & 0.671 & - \\
Item 3 & - & 0.630 & - \\
Item 4 & - & 0.614 & - \\
Item 2 & - & 0.500 & - \\
Item 1 & - & 0.373 & - \\
\hline Overall & - & - & $\mathbf{0 . 9 1}$ \\
\hline & & &
\end{tabular}


belonged to the hostility subscale; hence, component 2 was labelled 'hostility'.

As shown in Table 5, PCA was conducted on the 20 items of the JIS. The Kaiser-Meyer-Olkin and the Bartlett's test of sphericity values indicated that the data was suitable for analysis. A forced PCA retaining two components explained a total of $38.289 \%$ of the variance, with component 1 contributing $24.495 \%$ and component 2 contributing $13.793 \%$. Only 18 items showed significant loadings on the two-component solution with the exception of items 2 and 20, which were excluded from further analysis. No specific subscales have been established through previous research for this measure; however, Lodahl and Kejner (1965) did separate the items into four sub-dimensions when constructing this measure. The four sub-dimensions and their specific items are as follows: response to work (items $10,14,16,17,18,19)$, expression of being job involved $(2,3,6$, $7,9,11,15)$, sense of duty towards work $(1,4,8,12,20)$ and

TABLE 5: Exploratory factor analysis of the Job Involvement Scale.

\begin{tabular}{lccc}
\hline Item & \multicolumn{2}{c}{ Component } & Reliability \\
\cline { 2 - 3 } & $\mathbf{1}$ & $\mathbf{2}$ & \\
\hline Expression of being job involved & & & $\mathbf{0 . 8 1}$ \\
Item 11 & 0.691 & - & - \\
Item 3 & 0.677 & - & - \\
Item 8 & 0.652 & - & - \\
Item 6 & 0.649 & - & - \\
Item 15 & 0.643 & - & - \\
Item 9 & 0.639 & - & - \\
Item 7 & 0.615 & - & - \\
Item 1 & 0.569 & - & - \\
Item 4 & 0.517 & - & - \\
Item 12 & 0.499 & - & - \\
Item 5 & 0.438 & - & - \\
Response to work & - & - & - \\
Item 19 & - & 0.773 & - \\
Item 17 & - & 0.736 & - \\
Item 14 & - & 0.720 & - \\
Item 18 & - & 0.670 & - \\
Item 13 & - & 0.587 & - \\
Item 10 & - & 0.565 & - \\
Item 16 & - & 0.403 & - \\
\hline Overall & - & - & - \\
\hline
\end{tabular}

absenteeism and feelings of guilt about unfinished work (5, 13). Using this sub-dimension structure, it can be seen that the majority of items loading on component 1 belong to the expression of being job involved and sense of duty towards work sub-dimensions. Therefore, component 1 was labelled 'expression of being job involved' and component 2 was renamed 'response to work'.

\section{Pearson's product-moment correlation}

Pearson product-moment correlations were computed to determine the relationship between variables. The results of the Pearson correlation have been summarised in Table 6 .

As indicated in the Table 6, PsyCal displayed statistically negative relationships with uncivil workplace behaviour ( $p \leq$ $0.05)$ and hostility $(p=0.01)$. In addition, PsyCap yielded a statistically and practically significant relationship with job involvement $(p<0.01)$ (medium effect) and expression of being job involved $(p<0.01)$ (medium effect). Optimism displayed negative statistically significant relationships with job stress $(p \leq 0.05)$ and uncivil workplace behaviour $(p \leq 0.05)$. There was a statistically significant relationship between optimism and job involvement $(p<0.01)$ (medium effect) and expression of being job involved $(p=0.00)$ (large effect). Job stress displayed a statistically significant relationship with uncivil workplace behaviour $(p \leq 0.05)$ and hostility $(p=0.001)$. Job stress also yielded negative statistically and practically significant relationships with job involvement $(p=0.04)$ (medium effect) and response to work $(p<0.01)$ (medium effect). Uncivil workplace behaviour displayed a negative statistically and practically significant relationship with response to work ( $p=0.002)$ (medium effect). Of note also is that hostility displayed negative statistically significant relationships with response to work $(p=0.005)$. Expression of being job involved displayed a statistically and practically significant relationship with response to work $(p=$ 0.003) (medium effect).

\section{Multiple regression}

As indicated in Table 7 , both job stress $(\beta=0.224 ; p \leq 0.05)$ and PsyCap $(\beta=-0.234 ; p \leq 0.05)$ held predictive values

TABLE 6: Pearson product-moment correlation coefficients.

\begin{tabular}{|c|c|c|c|c|c|c|c|c|c|}
\hline Variable & 1 & 2 & 3 & 4 & 5 & 6 & 7 & 8 & 9 \\
\hline 1. Psychological capital & - & - & - & - & - & - & - & - & - \\
\hline 2. Hope-confidence & $0.96 * *+\dagger$ & - & - & - & - & - & - & - & - \\
\hline 3. Optimism & $0.63 * *+\dagger$ & $0.39 * * \dagger$ & - & - & - & - & - & - & - \\
\hline 4. Job stress & -0.11 & -0.03 & $-0.27 *$ & - & - & - & - & - & - \\
\hline 5. Uncivil workplace behaviour & $-0.26^{*}$ & $-0.22 *$ & $-0.20 *$ & $0.25 *$ & - & - & - & - & - \\
\hline $\begin{array}{l}\text { 6. Privacy invasion and } \\
\text { exclusionary behaviour }\end{array}$ & -0.19 & -0.19 & $-0.09 * * \dagger \dagger$ & 0.20 & 0.91 & - & - & - & - \\
\hline 7. Hostility & $-0.27 * *$ & $-0.20 *$ & $-0.29 * *$ & $0.28 * *$ & $0.91 * * \dagger \dagger$ & $0.65 * *+\dagger$ & - & - & - \\
\hline 8. Job involvement & $0.39 * * \dagger$ & $0.31 * * \dagger$ & $0.43 * * \dagger$ & $-0.32 * * \dagger$ & $-0.26^{*}$ & -0.19 & $-0.32 * * \dagger$ & - & - \\
\hline $\begin{array}{l}\text { 9. Expressions of being } \\
\text { job involved }\end{array}$ & $0.45 * * \dagger$ & $0.33 * * \dagger$ & $0.54 * *+\dagger$ & -0.16 & -0.14 & -0.03 & $-0.25^{*}$ & $0.87 * * \dagger \dagger$ & - \\
\hline 10. Response to work & 0.15 & 0.14 & 0.12 & $-0.39 * * \dagger$ & $-0.31 * * \dagger$ & $-0.30 * * \dagger$ & $-0.28 * *$ & $0.74 * *+\dagger$ & $0.32 * * \dagger \dagger$ \\
\hline
\end{tabular}

$* p \leq 0.05$, statistically significant;

$* *, p \leq 0.01$, statistically significant;

$\dagger, r>0.30$, practically significant (medium effect)

$\dagger, r>0.50$, practically significant (large effect). 
for incivility. In total the independent variables explained $34.1 \%$ of the variance in incivility although PsyCap showed evidence of a unique negative relationship $(p=0.030)$ with incivility and job stress revealed a positive significant relationship ( $p=0.037)$ with incivility.

\section{Hierarchical regression}

Hierarchical regression was used to determine whether the two independent variables (PsyCap and job stress) were able to predict, firstly, incivility and, secondly, job involvement. Additionally, the moderating role of PsyCap in the relationships between job stress and incivility and job stress and job involvement was assessed through an inspection of the interaction between PsyCap and job stress. The results of the hierarchical regression analysis are presented in Table 8a and Table $8 \mathrm{~b}$.

As indicated in Table $8 \mathrm{a}$ and Table $8 \mathrm{~b}$, the independent variables (PsyCap and job stress) entered in step 1, explained
$11.6 \%$ of the variance in incivility. In step 2, the computed interaction term ( $z$-score) for PsyCap and job stress explained $12.7 \%$ of the variance in incivility $(F=3.676 ; p=0.343)$. The addition of the interaction term indicated no statistically significant difference in the model, thereby suggesting that PsyCap did not moderate the relationship between job stress and incivility. Hierarchical regression was conducted to determine the predictive value of PsyCap and job stress on job involvement. In step 1, only the independent variables (PsyCap and job stress) were entered, explaining 22.5\% of the variance in job involvement. In step 2, the computed interaction term for PsyCap and job stress was entered into the model, accounting for $24.1 \%$ of the variance in job involvement $(F=7.851 ; p=0.203)$. The addition of the interaction term indicated no statistically significant difference in the model, suggesting that PsyCap did not moderate the relationship between job stress and job involvement. To further ensure the accuracy of this finding, hierarchical regression was conducted a second time. The new interaction terms were as follows: moderator 1 (hopeful

TABLE 7: Regression analyses with incivility as an independent variable and job stress and psychological capital (PsyCap) as dependent variables.

\begin{tabular}{|c|c|c|c|c|c|c|c|c|c|}
\hline \multirow[t]{2}{*}{ Model } & \multicolumn{2}{|c|}{ Unstandardised coefficients } & \multirow{2}{*}{$\frac{\text { Standardised coefficients }}{\text { Beta }}$} & \multirow[t]{2}{*}{$t$} & \multirow[t]{2}{*}{$p$} & \multirow{2}{*}{$\frac{F}{5.263}$} & \multirow{2}{*}{\begin{tabular}{c|}
$R$ \\
0.341
\end{tabular}} & \multirow{2}{*}{$\begin{array}{c}R^{2} \\
0.116\end{array}$} & \multirow{2}{*}{$\begin{array}{c}\Delta R^{2} \\
0.094\end{array}$} \\
\hline & B & SE & & & & & & & \\
\hline (Constant) & 25.385 & 5.891 & - & 4.309 & 0.000 & - & - & - & - \\
\hline Job stress & 0.257 & 0.121 & 0.224 & 2.119 & $0.037 *$ & - & - & - & - \\
\hline PsyCap & -0.129 & 0.059 & -0.234 & -2.210 & $0.030 *$ & - & - & - & - \\
\hline
\end{tabular}

*, Statistically significant, $p \leq 0.05$.

TABLE 8a: Hierarchical regression to determine the predictive value of the independent variables (psychological capital and job stress) on the dependent variable (incivility) in test 1 and the dependent variable (job involvement) in test 2.

\begin{tabular}{|c|c|c|c|c|c|c|c|c|}
\hline \multirow[t]{2}{*}{ Variable } & \multicolumn{8}{|c|}{ Total incivility } \\
\hline & $F$ & $B$ & SE & $R$ & $R^{2}$ & $\Delta \boldsymbol{R}^{2}$ & $t$ & $p$ \\
\hline \multicolumn{9}{|l|}{ Step 1} \\
\hline Constant & - & - & - & - & - & - & 25.922 & $0.000 * *$ \\
\hline Psychological capital & - & -0.234 & 0.886 & - & - & - & -2.168 & $0.001 *$ \\
\hline Job stress & 5.066 & 0.224 & 0.886 & 0.341 & 0.116 & 0.093 & 2.079 & $0.009 *$ \\
\hline \multicolumn{9}{|l|}{ Step 2} \\
\hline Constant & - & - & - & - & - & - & 25.891 & $0.000^{* *}$ \\
\hline Psychological capital & & -0.245 & 0.892 & - & - & - & -2.255 & $0.027 *$ \\
\hline Job stress & & 0.226 & 0.887 & - & - & - & 2.093 & $0.040 *$ \\
\hline Interaction between psychological capital and job stress & 3.676 & 0.103 & 0.686 & 0.356 & 0.127 & 0.092 & 0.954 & 0.343 \\
\hline
\end{tabular}

$F, F$-value; $B$, beta; $\mathrm{SE}$, standard error, $R$, square root of $R$-square (correlation between the observed and predicted values of the dependent variable); $R^{2}$, proportion of variance in the dependent variable explained by the independent variables; $\Delta R^{2}$, change in percentage variance explained by the next step in the model; $t, t$-statistic

variable explained by the inde.
$*, p<0.005 ; * *, p<0.001$.

TABLE 8b: Hierarchical regression to determine the predictive value of the independent variables (psychological capital and job stress) on the dependent variable (incivility) in test 1 and the dependent variable (job involvement) in test 2.

\begin{tabular}{|c|c|c|c|c|c|c|c|c|}
\hline \multirow[t]{2}{*}{ Variable } & \multicolumn{8}{|c|}{ Total job involvement } \\
\hline & $F$ & $B$ & SE & $R$ & $R^{2}$ & $\Delta R^{2}$ & $t$ & $p$ \\
\hline \multicolumn{9}{|l|}{ Step 1} \\
\hline Constant & - & - & - & - & - & - & 48.105 & $0.000^{* *}$ \\
\hline Psychological capital & & 0.356 & 1.050 & - & - & - & 3.484 & $0.001 *$ \\
\hline Job stress & 10.858 & -0.276 & 1.050 & 0.474 & 0.225 & 0.204 & -2.695 & $0.009 *$ \\
\hline \multicolumn{9}{|l|}{ Step 2} \\
\hline Constant & - & - & - & - & - & - & 48.013 & $0.000^{* *}$ \\
\hline Psychological capital & - & 0.370 & 1.052 & - & - & - & 3.615 & $0.001 *$ \\
\hline Job stress & - & -0.278 & 1.046 & - & - & - & -2.727 & $0.008^{*}$ \\
\hline Interaction between psychological capital and job stress & 7.851 & -0.131 & 0.809 & 0.491 & 0.241 & 0.211 & -1.284 & 0.203 \\
\hline
\end{tabular}

$F, F$-value; $B$, beta; $\mathrm{SE}$, standard error, $R$, square root of $R$-square (correlation between the observed and predicted values of the dependent variable); $R^{2}$, proportion of variance in the dependent variable explained by the independent variables; $\Delta R^{2}$, change in percentage variance explained by the next step in the model; $t, t$-statistic.

$*, p<0.005 ; * * p<0.001$. 
confidence and job stress) and moderator 2 (optimism and job stress). Each of these moderators was tested against, firstly, the outcome of incivility and, secondly, job involvement. In accordance with the findings reported for the analysis in Table $8 \mathrm{a}$ and Table $8 \mathrm{~b}$, no significant interactions were found to exist between each of the moderators and the outcomes of incivility and job involvement.

In Figure 1, the moderating effect of PsyCap in the relationship between job stress and incivility is indicated. It can be observed that there was no significant interaction displayed between the variables. This confirms the findings outlined in Table $8 \mathrm{a}$ and Table $8 \mathrm{~b}$, which indicated that the interaction term held no significant predictive value for the outcome of incivility. This suggests that PsyCap does not moderate the relationship between job stress and incivility.

In Figure 2, the moderating effect of PsyCap in the relationship between job stress and job involvement is displayed. It can be similarly noted, as in Figure 1, that no significant interaction effect was displayed, as no interaction occurred between the moderator and job stress and job involvement. This confirms the results outlined in Table 8a

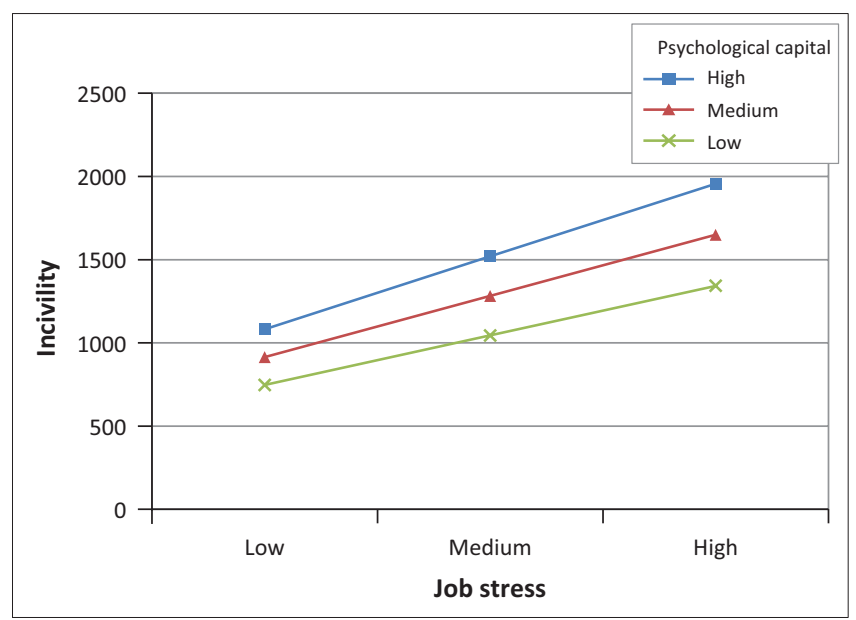

FIGURE 1: The moderating effect of psychological capital in the relationship between job stress and incivility.

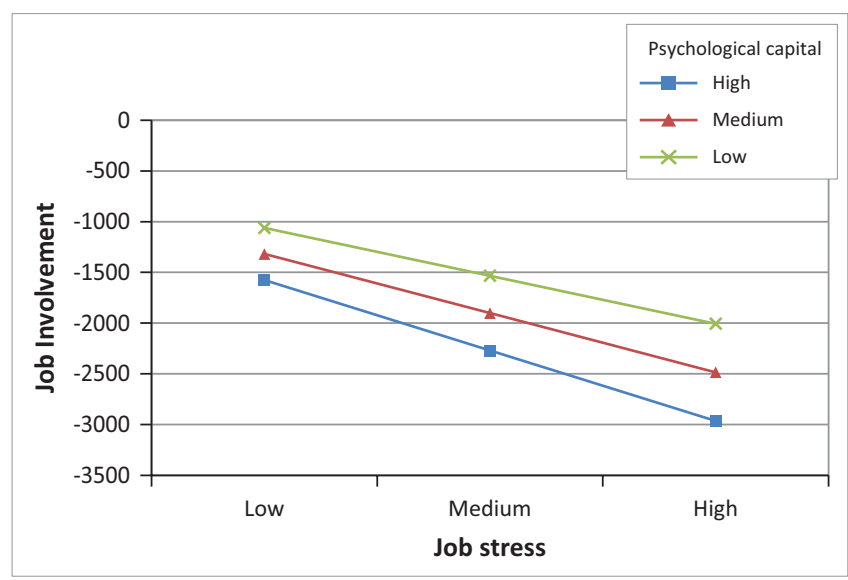

FIGURE 2: The moderating effect of psychological capital in the relationship between job stress and job involvement. and Table 8b, which indicated that the interaction term held no significant predictive value for the outcome of job involvement, suggesting that PsyCap did not moderate the relationship between job stress and job involvement.

\section{Discussion}

The primary objective of this study was to determine the relationship between PsyCap, job stress, incivility and job involvement, and to determine whether psychological capital and job stress hold any predictive value for the outcomes of incivility and job involvement.

\section{Factor structure of instruments}

One of the specific objectives of the study was to determine the factor structure of the various measuring instruments. Exploratory factor analysis of the PCQ found a two-factor model best suited the data. The factor structure of the PCQ in the current study does not entirely compare to the original four-factor structure determined by Luthans et al. (2007) in which self-efficacy, hope, optimism and resilience were identified as being the four factors present. Rather, it is clear that the sample in the current study did not appear to differentiate between self-efficacy and hope, resulting in the combining of these subscales to form 'hopefulconfidence'. The hopeful-confidence subscale was initially named by Du Plessis and Barkhuizen (2012) who, using a South African sample, similarly detected an inability to differentiate between self-efficacy and hope amongst their sample. The second PCQ factor consisted of a combination of items originally belonging to the optimism and resilience subscales, with a majority of the items belonging to the optimism subscale so that this factor was labelled 'optimism'.

In this study, job stress was regarded as a one-dimensional construct as this was deemed to suit the data best. The JSS displayed a high level of internal consistency with a Cronbach's alpha coefficient of 0.91 . This is in accordance with the Cronbach's alpha coefficient of 0.91 for the overall scale determined by Almendra (2010). Analysis of the UWBS found a two-factor model fitted the data best, as opposed to the four-factor model originally determined by Martin and Hine (2005) as the sample did not appear to differentiate between gossiping and hostility, resulting in the loading of items from both subscales on to one factor labelled 'hostility'; those items from privacy invasion and exclusionary behaviour were loaded onto one factor labelled 'privacy invasion and exclusionary behaviour'. This study, however, used the two factors determined through exploratory factor analysis in all analyses.

Analysis of the JIS determined that a two-factor model fitted the data best with further analysis concluding that job involvement appeared to be a multidimensional construct with at least three factors present. However, the factor structure of the scale appeared unstable due to its changing nature and they lacked clarity regarding the specific 
sub-dimensions. The items could be grouped into four subdimensions or themes that are important to job involvement (Govender \& Parumasur, 2010). These include; response to work, expressions of being job involved, sense of duty towards work and feelings about unfinished work and absenteeism. This study adopted the two-factor structure determined through exploratory factor analysis as this structure was deemed to best fit the sample.

\section{Relations between psychological capital, job stress, incivility and job involvement}

Another objective of this study was to determine the relationship between PsyCap, job stress, incivility and job involvement. The findings of the analysis indicated that PsyCap and uncivil workplace behaviour were negatively related, whilst PsyCap and job involvement were positively related. A stronger relationship was found between PsyCap and job involvement than between PsyCap and uncivil workplace behaviour. The negative relationship between PsyCap and uncivil workplace behaviour suggests that an individual possessing a high level of PsyCap may be less likely to engage in acts of incivility. A study by Avey et al. (2006) found a relationship between high levels of PsyCap and a decrease in the display of counterproductive behaviours at work. Similarly, Roberts et al. (2011) determined that individuals possessing high levels of PsyCap displayed less incivility than those with low levels of PsyCap. PsyCap displayed a stronger negative relationship with hostility than with overall uncivil workplace behaviour. This provides an indication of the specific nature of uncivil responses reduced, as individuals with high PsyCap are less likely to display hostility towards co-workers in the form of either rolling their eyes at a co-worker, speaking to a coworker in an aggressive tone of voice or gossiping behind a co-worker's back.

The positive relationship between PsyCap and job involvement suggests that an individual possessing a high level of PsyCap may display a high level of job involvement. The argument being that individuals possessing high levels of self-efficacy, hope, optimism and resilience may possess greater psychological resources to draw upon in achieving positive workplace outcomes such as job involvement. Interestingly, PsyCap displayed a stronger relationship with expressions of being job involved than with overall job involvement. This indicates that individuals with high PsyCap are more likely to be personally involved with their jobs and may consider the most important things that happen to them to be connected to their jobs.

The PsyCap dimension of hopeful-confidence displayed a positive relationship with job involvement and expressions of being job involved. This possibly suggests that individuals who are confident about engaging in workrelated behaviours and can perceive a number of different pathways to achieving their goals may be more involved in their jobs, which is expressed through the importance and centrality of work in their lives. Hopeful-confidence also displayed a negative relationship with uncivil workplace behaviour and hostility. However, a stronger relationship was found between hopeful-confidence and job involvement and expression of being job involved than between hopeful-confidence and uncivil workplace behaviour and hostility. The negative relationship between hopeful confidence and uncivil workplace behaviour and its sub-dimension of hostility possibly suggests that individuals who feel confident about participating in work-related activities and can determine multiple ways of achieving their desired outcomes are less likely to display hostile behaviour at work through acts such as gossiping about co-workers or speaking to co-workers in an aggressive tone of voice. Whilst previous research has examined the relationship between PsyCap and uncivil workplace behaviour (Roberts et al., 2011), each construct was studied as a whole and the specific sub-dimensions of each construct and the relationships between them were not studied.

Although PsyCap did not display a significant relationship with job stress, the optimism subscale displayed a negative relationship with job stress. This suggests that an individual experiencing a high level of optimism is likely to possess a low level of job stress. The present study examined job stress as an antecedent and not an outcome and, therefore, it should be noted that findings from the current study suggest that individuals experiencing greater levels of job stress reported lower levels of optimism and may, therefore, have fewer positive expectations of the future. Optimism also displayed a negative relationship with uncivil workplace behaviour and both its subscales, privacy invasion and exclusionary behaviour and hostility. This suggests that individuals possessing greater positive expectations for the future are less likely to display negative and uncivil workplace behaviours such as invading a co-worker's privacy, neglecting to pass on important information to a co-worker or raising their voice at a co-worker.

The findings of the Pearson product-moment correlation further indicated that job stress and uncivil workplace behaviour were positively related, whilst job stress and job involvement were negatively related. A stronger relationship was found between job stress and job involvement than between job stress and uncivil workplace behaviour. Previous research has similarly found a strong relationship between job stress and incivility, such as the study conducted by Penney and Spector (2005). This can be understood in the fact that individuals experiencing high levels of stress, as a result of the negative emotions experienced, are likely to react negatively by lashing out at others through acts of incivility. In this manner, the positive relationship between job stress and uncivil workplace behaviour, and hostility in particular, indicates that an individual experiencing a high level of stress in the workplace may form a negative appraisal of the situation and react in a negative and hostile manner towards others within the work environment. 


\section{Psychological capital and job stress as predictors of incivility and job involvement: The moderating role of PsyCap}

This study also sought to determine whether PsyCap and job stress held any predictive value for the outcomes of incivility and job involvement. Multiple regression analysis was conducted with hopeful-confidence, optimism and job stress as the independent variables in all the analyses. The findings indicated that job stress held predictive value for incivility and the hostility subscale; PsyCap did not display significant predictive value for incivility. Instead, job stress was determined to hold significant predictive value for incivility and the hostility subscale in particular. This implies that an individual reporting a high level of stress can be expected to also exhibit uncivil and counterproductive workplace behaviour that may be hostile in nature. Multiple regression analysis further indicated that the PsyCap subscale of optimism held strong predictive value for job involvement and the expression of being job involved subscale. This suggests that optimistic employees who generally have positive expectations of the future can be expected to be more involved in their work and to engage in behaviour that indicates their enthusiasm and interest in their work. Further, it was found that job stress held predictive value for job involvement and the response to work subscale. This may be as a result of employees' expectations regarding their work having not being met, resulting in a less-than-enthusiastic response to work. Hierarchical regression analysis indicated that whilst PsyCap and job stress held significant predictive value for incivility and job involvement, there was no significant interaction effect as addition of the interaction term (psychological capital $\times$ job stress) in the second step of each analysis resulted in no significant interaction with incivility and job involvement. This indicated that PsyCap did not moderate the relationship between job stress and incivility and neither did it moderate the relationship between job stress and job involvement creativity.

\section{Conclusions and recommendations}

The findings revealed positive relationships between job stress and incivility, indicating that high levels of job stress are associated with high levels of incivility. Job stress was also found to have predictive value for incivility. This suggests a need for organisations to seek ways to reduce job stress in order to lower the risk of incivility being displayed by employees. Results revealed that high levels of job stress were associated with low levels of job involvement. This may, interestingly, be suggesting that ways of reducing job stress should be determined so that employees' levels of job involvement may increase. The study found that high levels of job stress are more likely to predict low levels of job involvement, further confirming the need for determining ways of reducing job stress in order to enhance employee job involvement. In addition, a negative relationship existed between job stress and PsyCap, implying that organisations should work on minimising stressors within the workplace (e.g implementing stress management interventions, adjusting workloads and increasing the level of autonomy) in order to enhance the psychological capital of employees. Moreover, job rotation can be implemented to alleviate the effects of stress associated with a particular job, at the same time granting variety of tasks, preventing the onset of conditions such as Cumulative Trauma Disorder and reducing the risk of boredom (Smith, 2002). A positive relationship between PsyCap and job involvement encourages organisations to invest in training that is aimed at improving the PsyCap of employees in order to increase their level of job involvement. Luthans, Avey, Avolio, Norman and Combs (2006) have demonstrated the utility of interventions aimed at improving PsyCap through an hour-long micro-intervention conducted amongst a sample of management students and managers from several organisations. If implemented correctly within the workplace, such interventions would not only prove efficient by minimising costs and the time required to implement the intervention, but would also ensure greater willingness amongst employees to participate in the intervention.

\section{Limitations of the study}

As with most studies, the present study has its limitations. Firstly, the small sample size of 104 participants limits the generalisability of the findings in other contexts. Secondly, self-report questionnaires such as the UWBS were used in the study. This normally leads to participants providing socially desirable responses, which may comprise the accuracy of the findings. Socially desirable responding is a common problem especially when self-report questionnaires are used. Whilst significant relationships between variables were determined in the present study, causal relationships could not be inferred from these findings. This is because the current study used a cross-sectional research design in which data was collected at a fixed point in time and this limits the determination of causal relationships amongst variables. In order for causality to be determined in similar and related studies, future researchers are encouraged to adopt a longitudinal research design to study the same phenomenon at different points in time.

\section{Suggestions for future research}

Future research endeavours in this area of study should consider providing desirable incentives for individuals to willingly participate in the study, rather than relying on individual's sense of duty towards the organisation to provide adequate incentive to participate. This may achieve a higher response rate and possibly more honest responses, which would ensure more reliable findings. In spite of the various limitations of the study, future research can further examine the relationship between PsyCap, job stress, incivility and job involvement. In terms of the findings of the present study, future research can explore the relationships determined in the study, especially the relationship between job stress and job involvement, PsyCap and job involvement and job involvement and incivility, as there is a noticeable lack of research examining these constructs in relation to each other. 


\section{Acknowledgements}

\section{Competing interests}

The authors declare that they have no financial or personal relationships that may have inappropriately influenced them in writing this article.

\section{Authors' contributions}

S.B. (University of KwaZulu-Natal) was the master's student and the project leader. J.H. (University of KwaZulu-Natal) was the study leader and H.K. (University of the Free State) assisted with the statistical analysis.

\section{References}

Almendra, C.A. (2010). Relationships among Job demand, job control, social suppor and job stress in registered nurses working in skilled nursing facilities. Unpublished doctoral dissertation, Department of Psychology, State University of New Jersey, New Brunswick, NJ.

Andersson, L.M., \& Pearson, C.M. (1999). Tit for tat? The spiralling effect of incivility in the workplace. Academy of Management Review, 24, 452-471. http://dx.doi. org/10.2307/259136

Avey, J.B., Luthans, F., \& Youssef, C.M. (2006). The additive value of positive psychological capital in predicting work attitudes and behaviours. Journal of Management, 36(20), 430-452.

Bandura, A. (2008). An agentic perspective on positive psychology. In S.J. Lopez (Ed.) Positive psychology: Exploring the best in people (Vol. 1, pp. 167-196). Westport CT: Greenwood.

Banks, D., \& Roodt, G. (2011). The efficiency and quality dilemma: What drives South African call centre management performance indicators? South African Journal of Human Resource Management, 9(1), Art. \#331, 17 pages.

Beehr, T.A., \& Newman, J.E. (1998). Research on occupational stress: An unfinished enterprise. Personnel Psychology, 51, 835-844. http://dx.doi. org/10.1111/j.1744-6570.1998.tb00741.x

Benner, C., Rahmat, O., \& Lewis, C. (2007). The South African call centre industry: National benchmarking report, strategy. HR Practices \& Performance. Johannesburg, South Africa: Sociology of Work Unit and Link Centre, University of Witwatersrand.

Bosman, J., Buitendach, J.H., \& Rothmann, S. (2005). Work locus of control and dispositional optimism as antecedent to job insecurity. South African Journal of Industrial Psychology, 31(4), 17-23.

Clark, L.A., \& Watson, D. (1995). Constructing validity: Basic issues in objective scale development. Psychological Assessment, 7, 309-319. http://dx.doi. org/10.1037/1040-3590.7.3.309

Cohen, J. (1988). Statistical power analysis for the behavioural sciences (2nd edn.) Hillside, NJ: Erlbaum. http://dx.doi.org/10.1002/bs.3830330104

Coon, D., \& Mitterer, J.O. (2007). Introduction to psychology: Gateways to mind and behaviour (11th edn.). Belmont, CA: Wadsworth.

Coutu, D.L. (2002). How resilience works. Harvard Business Review, 80(5), 46-55.

Du Plessis, Y., \& Barkhuizen, N. (2012). Psychological capital, a requisite for organisational performance in South Africa. South African Journal of Economic and Management Sciences, 15(1), 132-159.

Durrheim, K., \& Painter, D. (2006). Collecting quantitative data. In M. Terre Blanche, K. Durrheim, \& D. Painter (Eds.), Research methods in practice: Applied methods for the social sciences (2nd edn., pp. 132-134), Cape Town, South Africa: UCT Press.

Fredrickson, B.L. (2004). The broaden-and-build theory of positive emotions. The Royal Society, 359, 1367-1377.

Govender, S., \& Parumasur, S.B. (2010). The relationship between employee motivation and job involvement. South African Journal of Economic and Management Sciences, 13(3), 237-253.

Herbert, M. (2011). An exploration of the relationships between psychological capital (hope, optimism, self-efficacy, resilience), occupational stress, burnout and employee engagement. Unpublished master's thesis, Department of Industrial Psychology, Stellenbosch University, Cape Town, South Africa.

Holman, D., Batt, R., \& Holtgrewe, U. (2007). The global call centre report: International perspectives on management \& employment. Report of the Global Call Centre Network, Global Call Centre Project, School of Industrial and Labour Relations, Cornell University, Ithaca, NY.

Howell, D.C. (2008). Fundamental statistics for the behavioural sciences (6th edn.) Belmont, CA: Wadsworth

Janse van Rensburg, Y., Boonzaier, B., \& Boonzaier, M. (2013). The job demands resources model of work engagement in South African call centres. South African Journal of Human Resource Management, 11(1), Art. \#484, 13 pages. http:// dx.doi.org/10.4102/sajhrm.v11i1.484

Kanungo, R.N. (1982). Measurement of job and work involvement. Journal of Applied Psychology, 67(3), 341-349. http://dx.doi.org/10.1037/0021-9010.67.3.341
Lata-Juyal, S. (2012). Occupational stress and job involvement among managers. Global Journal of Management Science and Technology, 1(4), 1-12.

Lazarus, R.S., \& Folkman, S. (1984). Stress, appraisal and coping. New York, NY: Springer.

Lewis, S. (2011). Positive psychology at work: How positive leadership and appreciative inquiry create inspiring organisations. Oxford, UK: Wiley-Blackwell. http://dx.doi. org/10.1002/9781119990390

Lodahl, T. M., \& Kejner, M. (1965). The definition and measurement of job involvement. Journal of Applied Psychology, 49, 24-33. http://dx.doi.org/10.1037/h0021692

Luthans, F. (2002). The need for and meaning of positive organisational behaviour. Journal of Organisational Behaviour, 23, 695-706. http://dx.doi.org/10.1002/ job.165

Luthans, F., \& Youssef, C.M. (2004). Human, social, and now positive psychological capital management: Investing in people for competitive advantage. Organisational Dynamics, 33(2), 143-160. http://dx.doi.org/10.1016/j.orgdyn.2004.01.003

Luthans, F., Avey, J.B., Avolio, B.J., Norman, S.M., \& Combs, G.M. (2006). Psychological capital development: Toward a micro-intervention. Journal of Organisationa Behaviour, 27, 387-393. http://dx.doi.org/10.1002/job.373

Luthans, F., Youssef, C.M., \& Avolio, B.J. (2007). Psychological capital. New York, NY: Oxford University Press.

Martin, R.J., \& Hine, D.W. (2005). Development and validation of the Uncivil Workplace Behaviour Questionnaire. Journal of Occupational Psychology, 10, 477-490. http://dx.doi.org/10.1037/1076-8998.10.4.477

Masten, A.S., \& Reed, M.G.J. (2002). Resilience in development. In C.R. Snyder, \& S. Lopez (Eds.), Handbook of positive psychology (pp. 74-88). Oxford, UK: Oxford University Press. http://dx.doi.org/10.1007/0-306-47167-1_12

Nunnally, J.C., \& Bernstein, I.H. (1994). Psychometric theory. New York, NY: McGrawHill.

Ouyang, Y. (2009). The mediating effects of job stress and job involvement under job instability: Banking service personnel of Taiwan as an example. Journal of Money Investment and Banking, 11, 16-26.

Parker, D.F., \& DeCotiis, T.A. (1983). Organisational determinants of job stress. Organisational Behaviour and Human Performance, 32, 160-177. http://dx.doi. org/10.1016/0030-5073(83)90145-9

Pearson, C.M., \& Porath, C.L. (2009). Introduction. In C.M. Pearson, \& C.L. Porath (Eds.), The cost of bad behaviour: How incivility is damaging your business and what to do about it (pp. 3-8). New York, NY: Penguin.

Penney, L.M., \& Spector, P.E. (2005). Job stress, incivility, and counterproductive work behaviour (CWB): The moderating role of negative affectivity. Journal of Organisational Behaviour, 26, 777-796. http://dx.doi.org/10.1002/job.336

Peterson, C. (2000). The future of optimism. American Psychologist, 55, 44-55. http:// dx.doi.org/10.1037/0003-066X.55.1.44

Ramsey, R., Lassk, F.G., \& Marshall, G.W. (1995). A critical evaluation of a measure of job involvement: The use of the Lodahl and Kejner (1965) scale with salespeople. Journal of Personal Selling and Sales Management, 15(3), 65-74.

Roberts, S.J., Scherer, L.L., \& Bowyer, C.J. (2011). Job stress and incivility: What role does psychological capital play? Journal of Leadership and Organisational Studies, 18(4), 449-458.

Rothmann, S., \& Cilliers, F.V.N. (2007). Present challenges and some critical issues for research in industrial/organisational psychology in South Africa. South African Journal of Industrial Psychology, 33(1), 8-17.

Seligman, M.E.P. \& Csikszentmihalyi, M. (2000). Positive psychology: An introduction. American Psychologist, 55, 5-14. http://dx.doi.org/10.1037/0003-066X.55.1.5

Smith, S. (2002). Multiskilling. In M. Meyer (Ed.), Managing human resource development: An outcomes-based approach (2nd edn.). Durban, South Africa: LexisNexis Butterworths.

Snyder, C.R. (2000). Handbook of hope. San Diego, CA: Academic Press. http://dx.doi. org/10.1016/B978-012654050-5/50002-6

Snyder, C.R., Irving, L., \& Anderson, J. (1991). Hope and health: Measuring the will and the ways. In C.R. Snyder \& D.R. Forsyth (Eds.), Handbook of social and clinical psychology (pp. 285-305). Elmsford, NY: Pergamon.

Spector, P.E., \& Fox, S. (2005). An emotion-centred model of voluntary work behaviour: Some parallels between counterproductive work behaviour (CWB) and organisational citizenship behaviour (OCB). Human Resource Management Review, 12, 269-292. http://dx.doi.org/10.1016/S1053-4822(02)00049-9

SPSS version 21 [Computer software] (2012). Chicago, IL: IBM SPSS Inc.

Stajkovic, A.D., \& Luthans, F. (1998). Social cognitive theory and self-efficacy: Going beyond traditional motivational and behavioural approaches. Organisationa Dynamics, 26, 62-74. http://dx.doi.org/10.1016/S0090-2616(98)90006-7

Tiger, L. (1971). Optimism: The biology of hope. New York, NY: Simon \& Schuster.

Totterdell, P., Wood, S., \& Wall, T. (2006). An intra-individual test of the demandscontrol model: A weekly diary study of psychological strain in portfolio workers. Journal of Occupational and Organisational Psychology, 79, 63-85. http://dx.doi. org/10.1348/096317905X52616

Tugade, M.M., \& Fredrickson, B.L. (2004). Resilient individuals use positive emotions to bounce back from negative emotional experiences. Journal of Personality and Social Psychology, 86, 320-333. http://dx.doi.org/10.1037/0022-3514.86.2.320

Van Jaarsveld, D.D., Walker, D.D., \& Skarlicki, D.P. (2010). The role of job demands and emotional exhaustion in the relationship between customer and employee incivility. Journal of Management, 36(6), 1486-1504. http://dx.doi. org $/ 10.1177 / 0149206310368998$

Wood, S., \& Wood, E. (1996). The world of psychology (2nd edn.). USA: Allyn and Bacon. 